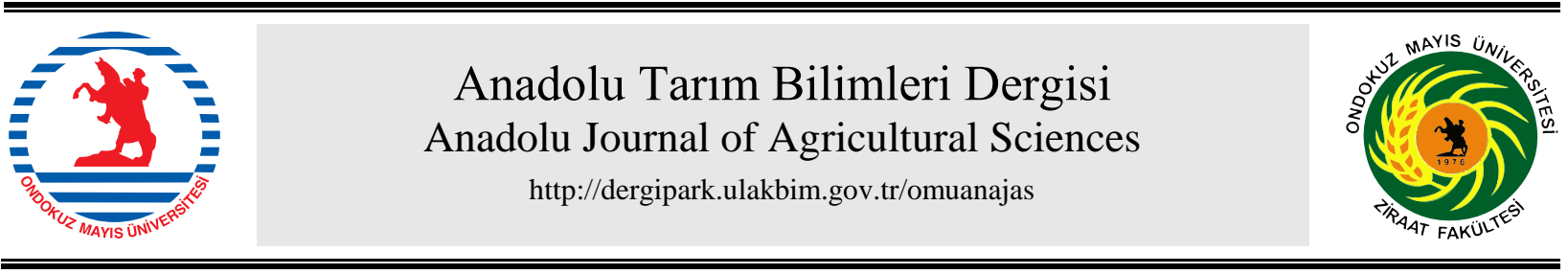

Araştırma/Research

Anadolu Tarım Bilim. Derg./Anadolu J Agr Sci, 31 (2016) ISSN: 1308-8750 (Print) 1308-8769 (Online) doi: 10.7161/omuanajas.260971

\title{
Bazı bölgesel organik atıkların topraksız tarımda (torba kültürü) kullanılabilme imkanlarının belirlenmesi
}

\author{
İsmail Dönmez ${ }^{a}$, Harun Özer ${ }^{a *}$, Coşkun Gülser ${ }^{b}$ \\ ${ }^{a}$ Ondokuz Mayls Üniversitesi Ziraat Fakültesi Bahçe Bitkileri Bölümü 55139 Atakum, Samsun \\ ${ }^{b}$ Ondokuz Mayı Üniversitesi Ziraat Fakültesi Toprak Bilimi ve Bitki Besleme Bölümü 55139 Atakum, Samsun \\ *Sorumlu yazar/corresponding author: haruno@omu.edu.tr
}

Geliş/Received 13/11/2015 Kabul/Accepted 09/02/2016

\begin{abstract}
ÖZET
$\mathrm{Bu}$ çalışma, topraksız tarımda serada yetiştirilen Bandita F1 salkım domates çeşidinin (Solanum lycopersicum L.) verim ve kalitesi üzerine bazı bölgesel organik atıklardan (fındık zurufu, çeltik kavuzu ve çay atığı) elde edilen (I. ve II.) ortamlar ile kaya yünü ve Hindistan cevizi lifi ortamlarının etkilerinin belirlenmesi amacıyla yürütülmüştür. Çalışmada, farklı yetiştirme ortamlarının meyve rengi (L, chroma ve hue $\left.{ }^{\circ}\right)$ ve suda çözünebilir kuru madde (\%), değerleri üzerine önemli etkilerinin olduğu tespit edilmiştir $(\mathrm{P}<0.05)$. Sonuçlara göre, en yüksek verim $3.07 \mathrm{~kg}$ ile Hindistan cevizi lifi ortamında belirlenmiştir. Çalışmada, kaya yünü ortamında yapılan yetiştiricilik ile meyve eti sertliği (44.96 N) diğer ortamlara göre daha yüksek bulunurken, en yüksek suda çözünebilir kuru madde içeriği ise \%6.7 ile I. yetiştirme ortamında belirlenmiştir. Araştırmanın sonuçlarına göre verim ve kalite yönünden Hindistan cevizi lifi ortamı öne çıkmasına rağmen bölgesel yetiştirme ortamların kullanılması ile verim ve kalite yönünden istatistiki olarak önemli bir farklılık tespit edilememiştir.
\end{abstract}

Determination of the usage possible of some regional organic wastes in soilless agriculture (bag culture)

\section{ABSTRACT}

This study was carried out to determine the effects of media (hazelnut husk, rice husk and tea waste) (I and II) obtained from several regional organic wastes with rockwool and cocopeat on yield and quality of Bandita F1 (Solanum lycopersicum L.) tomato varieties in soilless culture in greenhouse condition. In this study, the effect of the different growing medium on fruit color $\left(\mathrm{L}, \mathrm{chroma}\right.$ and hue $\left.{ }^{\circ}\right)$ and soluble solids contend (\%) values $(\mathrm{P}<0.05)$ was determined. According to the results, the highest yield $(3.07 \mathrm{~kg})$ was determined from cocopeat medium. In the study, fruit firmness performed with cultivation in the rockwool media (44.96 N) was higher than those in other media, the highest total soluble solids content was determined from the I. growth media with the $6.7 \%$. According the results of the research, although the use of cocopeat looks promising in terms of yield and quality, there is no statistically significant differences in terms of yield and quality by the use of regional growth medium.
Anahtar Sözcükler: Domates

Topraksız yetiştiricilik Yetiştirme ortamı

\section{Giriş}

Dünya sebze üretimi 2014 y1lında 1.1 milyar ton seviyesinde olup, domates 347 milyon ton üretimi ile dünya sebze üretiminde birinci sirada yer almaktadır (FAO, 2015). Ülkemiz 27.8 milyon ton sebze üretimi ile dünya dördüncü sırada yer almaktadır. Sebze üretimimizin yaklaşık \%87'si açıkta ve \%13'lük kısmı ise örtü altında gerçekleştirilmektedir. Serada üretilen sebze türleri arasında ilk sirada domates yer almakta, daha sonra sırası ile hiyar, biber ve patlıcan gelmektedir (Tüzel ve ark., 2015). Örtüaltı sebze yetiştiriciliğinde son yıllarda görülen artış beraberinde gerek tarımsal ilaçların, gerekse de gübrelerin bilinçsizce kullanımını ortaya çıkarmıştır. Toprağın derinlerine sızan fosfor ve nitrat tatlı su kaynaklarına ulaşmakta ve kimyasal tarım ilaçları toprakta birikerek insan ve çevre sağlığını olumsuz yönde etkileyerek ekolojik dengeyi bozmaktadır. Seralarda monokültür nedeniyle, toprakta hastalık ve zararlı yoğunluğu artmakta ve topraklar çabuk bozulmaktadır. Bunun yanında sera örtüsü seralarda toprakların yağmurun yararlarından yoksun bırakmakta ve yıkanmama nedeniyle tuzluluk önemli bir sorun oluşturmaktadır. Sera bitkilerinin ömürlerinin 
uzunluğu, güçlü hibrit çeşitler, yüksek verim, bitki artıklarının bırakılmaması ve yaz aylarındaki yüksek sıcaklıklar nedeniyle organik madde parçalanmasının artmas1, dezenfeksiyonlarla toprağı besince zenginleştiren solucanların yaşama şansının sinırlandırılması, toprağın bozulmasına neden olan diğer etmenlerdir. Sera topraklarında tüm iyileştirme ve dezenfeksiyon çalışmaları yapılsa dahi, yukarıda belirtilen olumsuzluklar tamamen ortadan kalkmamakta ve her 4-5 yılda bir toprağın değiştirilmesi gerekmektedir (Sevgican, 1989; 2003; Başar, 1995; Gül, 2008)

Dünyada ve ülkemizde örtüaltı sebze yetiştiriciliğinde, başta çevre kirliliği ve toprak kaynaklı sorunların artması olmak üzere pek çok nedenden dolayı geleneksel yetiştirme sistemleri terk edilmekte ve bunun yerine ise topraksız kültür yetiştirme sistemleri kullanılmaya başlanılmıştır (Aydoğan ve Gül, 1999; Tüzel ve ark., 2007). Toprağın bitkisel üretime uygun olmadığı yerlerde bitki yetiştiriciliğine imkan vermesi, bitki gelişimi ve ürün kalitesinin kontrol altında tutulabilmesine ve su kullanım etkinliğini artırması gibi üstünlüklere de sahip olması nedeniyle pek çok ülkede ticari sera üretiminde topraksız tarım önemli ölçüde benimsenmiştir (Özgümüş ve Kaplan, 1992; Sevgican, 2003; Gül, 2008). Bütün bu avantajlarından dolayı yaygınlaşan topraksız tarım alanları ülkemizde yaklaşık 7000 dekara ulaşmıştır (Şentürk, 2012).

Topraksız yetiştiricilikte organik, inorganik ve sentetik yetiştirme ortamları kullanılmaktadır (Leonardi, 2004; Gül, 2008). Dünyada ve Türkiye'de torf kaynaklarının tüketilmesi, perlit rezervlerinin azalması, kaya yününün atık problemi gibi nedenler yerel kaynaklardan topraksız tarıma uygun, kolay ve ucuz bulunabilen materyallere ilgiyi arttırmıştır (Frolking ve ark., 2001; Tüzel ve Gül, 2008).

Dünyada ve ülkemizde tarımsal üretimin artışıla beraber hem bitkisel hasat atıkları hem de tarımsal endüstri atıkları miktarları yıldan yıla artış göstermektedir. Bitkisel kökenli atıklar; ciddi bir organik madde kaynağı olmanın yanı sıra içermiş oldukları bitki besin maddeleri yönünden de önemli bir potansiyele sahiptirler. Günümüzde bu atıklardan uygun karışımlar elde edilerek bitki yetiştirme ortamı olarak kullanılabilmektedir. Bitkinin stres koşullarına karşı direncini arttırmak başta olmak üzere bazı olumsuz koşulların önüne geçebilmek için topraksız tarımda kullanılan yetiştirme ortamını hazırlarken iki veya daha fazla materyalin karışımının kullanılması gerektiği bildirilmektedir (Çıtak ve ark., 2007; Özer ve Uzun,
2013). Ülkemizde henüz ticari olarak yerel kaynaklardan elde edilmiş özgün bir yetiştirme ortamı bulunmamaktadır. Ekonomik ve çevresel atık yönetimi gibi faktörler nedeniyle bölgemize özgü bir yetiştirme ortamı oluşturulmasının önemini büyüktür (Varış ve Eminoğlu, 2003). Bu nedenle yapılan bu çalışma ile, topraksız tarımda kullanılabilecek alternatif organik yetiştirme ortamları ile ticari yetiştirme ortamlarının Samsun ekolojik koşullarında son turfanda topraksız salkım domates yetiştiriciliğinde verim ve kalite üzerine etkilerinin belirlenmesi amaçlanmıştır.

\section{Materyal ve Yöntem}

Çalışma, 28 Haziran - 15 Aralık 2013 tarihleri arasında Ondokuz Mayıs Üniversitesi Ziraat Fakültesi Sera Sitesinde yürütülmüştür. Araştırmada kullanılan sera $\left(120 \mathrm{~m}^{2}\right)$ PE plastik (antifog, antivirüs, infrared ve ultraviyole katkılı) materyali ile örtülü, yarım yay şekilli, çatıdan ve yandan tek taraflı havalandırmaya sahiptir.

Çalışmada bitkisel materyal olarak ticari fide firmasından temin edilmiş, örtüaltı yetiştiriciliğinde özellikle topraksız tarıma uygun Bandita F1 salkım domates çeşidinin fideleri kullanılmıştır. Çalışmada oluşturulan 4 farklı yetiştirme ortamından ikisi bölgesel organik atıklar kullanılarak oluşturulmuştur. Bu amaçla findık zurufu (kaba ve ince), çeltik kavuzu, çay atığı (kaba ve ince), yanmış çiftlik gübresi ve bahçe toprağından (Izorph7, doğal organik mineralli Kars toprağı) oluşan iki adet organik yetiştirme ortamı $21 \mathrm{~L}$ torbalara doldurulmuştur (Çizelge 1). Kaya yünü $(100 \times 15 \times 7.5 \mathrm{~cm})$ ve Hindistan cevizi lifi $(100 \times 20 \times 5 \mathrm{~cm})$ ise ticari yetiştirme ortamları olarak kullanılmıştır.

Hazırlanan yetiştirme ortamları, serada $16 \mathrm{~m}$ uzunluğunda, $25 \mathrm{~cm}$ eninde ve $\% 1.5$ eğimli torba kanallarına yerleştirilmiştir. Yetiştirme ortamlarının kül ve organik madde analizleri kül firınında kuru yakma yöntemi ile yapılmıştır. EC ve $\mathrm{pH}$ analizleri kaya yünü ortamları 1:2 oranında, Hindistan cevizi lifi ortamları 1:4 oranında ve ortam I ve ortam II örnekleri ise 1:1 oranında su-örnek karışımında yapılmıştır (Jackson, 1967). Na (ppm) ve K (ppm) analizleri flame fotometre de fotometrik yöntemle yapılmıştır. Organik madde ve kül analizleri kül firınında $550^{\circ} \mathrm{C}^{\prime}$ de kuru yakma yöntemi ile yapılmıştır (Kacar, 1994). Yetiştirme ortamlarından çalışmanın başında ve sonunda alınan örneklerin analiz sonuçlarına göre elde edilen besin elementi içerikleri Çizelge 2'de verilmiştir.

Çizelge 1. Organik yetiştirme ortamlarının karışım miktarları

\begin{tabular}{lccccccc}
\hline & $\begin{array}{c}\text { Fındık zurufu } \\
\text { (Kaba) }\end{array}$ & $\begin{array}{c}\text { Fındık } \\
\text { zurufu (İnce) }\end{array}$ & $\begin{array}{c}\text { Çeltik } \\
\text { kavuzu }\end{array}$ & $\begin{array}{c}\text { Çay atığı } \\
\text { (Kaba) }\end{array}$ & $\begin{array}{c}\text { Çay atığı } \\
\text { (İnce) }\end{array}$ & $\begin{array}{c}\text { Yanmış çiftlik } \\
\text { gübresi }\end{array}$ & $\begin{array}{c}\text { Bahçe } \\
\text { toprağ } 1\end{array}$ \\
\hline Ortam I & $7.35^{*}$ & 1.05 & 4.20 & 3.15 & 2.10 & 2.1 & 1.05 \\
Ortam II & 4.20 & 1.05 & 7.35 & 2.10 & 3.15 & 2.1 & 1.05 \\
\hline
\end{tabular}

$* \mathrm{~L}$ 
Çizelge 2. Çalışmada kullanılan yetiştirme ortamlarının analiz sonuçlarına göre bazı besin elementi içerikleri

\begin{tabular}{|c|c|c|c|c|c|c|c|}
\hline Ortamlar & & $\mathrm{pH}$ & $\begin{array}{c}\mathrm{EC} \\
\left(\mathrm{dS} \mathrm{m}^{-1}\right)\end{array}$ & $\begin{array}{l}\text { Kül } \\
(\%)\end{array}$ & $\begin{array}{c}\text { Organik madde } \\
(\%)\end{array}$ & $\begin{array}{c}\mathrm{Na} \\
(\mathrm{ppm})\end{array}$ & $\begin{array}{c}\mathrm{K} \\
(\mathrm{ppm})\end{array}$ \\
\hline Ortam I & & 7.34 & 3.0 & 52 & 48 & 800 & 9500 \\
\hline Ortam II & İlk ölçümler & 7.49 & 2.0 & 52 & 48 & 11666 & 9445 \\
\hline Kaya yünü & & 7.99 & 0.4 & 64 & 0 & 5000 & 3818 \\
\hline Hindistan cevizi lifi & & 5.70 & 1.2 & 13 & 87 & 820 & 4400 \\
\hline Ortam I & & 6.85 & 1.7 & 52 & 48 & 800 & 4050 \\
\hline Ortam II & Son ölçümler & 7.22 & 1.5 & 53 & 47 & 1310 & 4920 \\
\hline Kaya yünü & & 7.28 & 3.0 & 73 & 0 & 3818 & 1636 \\
\hline Hindistan cevizi lifi & & 5.85 & 3.0 & 10 & 90 & 750 & 960 \\
\hline
\end{tabular}

Yetiştirme ortamları ile doldurulmuş yetiştirme torbalarına Bandita F1 domates çeşidine ait hazır fideler 28.06.2013 tarihinde sira aras1 $150 \mathrm{~cm}$ ve sira üzeri 30 $\mathrm{cm}$ olacak şekilde dikilmiştir. Dikimi gerçekleştirilen fidelerin ortalama boyları $20.17 \mathrm{~cm}$, gövde çapları 3.86 $\mathrm{mm}$ ve yaprak sayıları ise 5.33 adet olarak tespit edilmiştir. Dikimden sonra, gübrelemede kullanılan makro ve mikro besin elementleri $300 \mathrm{~L}$ hacimli iki adet tankta A ve B stok çözeltisi olarak hazırlanmıştır (Çizelge 3). Gübreleme yetiştirme periyodu boyunca 20 dakika süresince iki saatlik aralıklarda (günde 5 defa) damlama sulama sistemi ile birlikte yapılmıştır. Yetiştirme periyodu boyunca stok çözeltilerin bulunduğu tanklar 2 ila 3 günde bir tekrar hazırlanmıştır.

Çizelge 3. Gübrelemede kullanılan makro ve mikro besin solüsyonları ve oranları

\begin{tabular}{|c|c|c|c|c|c|c|}
\hline \multicolumn{7}{|c|}{ Stok Çözeltiler (300 L) } \\
\hline \multirow{4}{*}{ A } & Kalsiyum Nitrat & Demir (\%6) & Potasyum & Potasyum & \multicolumn{2}{|l|}{ Nitrik Asit } \\
\hline & $\mathrm{Ca}\left(\mathrm{NO}_{3}\right) 2 \cdot 4 \mathrm{H}_{2} \mathrm{O}$ & Fe EDDHA & Nitrat & Klorür & \multirow{2}{*}{\multicolumn{2}{|c|}{$\mathrm{HNO}_{3}$}} \\
\hline & & & $\mathrm{KNO}_{3}$ & $\mathrm{KCl}$ & & \\
\hline & $468 \mathrm{~g}$ & $24 \mathrm{~g}$ & $90 \mathrm{~g}$ & $12 \mathrm{~g}$ & \multicolumn{2}{|l|}{$30 \mathrm{cc}$} \\
\hline \multirow{8}{*}{ B } & Mono Potasyum & Potasyum & Potasyum & Sodyum & \multirow{2}{*}{\multicolumn{2}{|c|}{$\begin{array}{l}\text { Mağnezyum Sülfat } \\
\text { MgSO }_{4} \cdot 7 \mathrm{H}_{2} \mathrm{O}\end{array}$}} \\
\hline & Fosfor & Sülfat & Nitrat & Molibdat & & \\
\hline & $\mathrm{KH}_{2} \mathrm{PO}_{4}$ & $\mathrm{~K}_{2} \mathrm{SO}_{4}$ & $\mathrm{KNO}_{3}$ & $(\% 40)$ & & \\
\hline & & & & & & \\
\hline & $78 \mathrm{~g}$ & $36 \mathrm{~g}$ & $160 \mathrm{~g}$ & $0.12 \mathrm{~g}$ & \multicolumn{2}{|l|}{$2.4 \mathrm{~g}$} \\
\hline & $\begin{array}{ll}\begin{array}{l}\text { Mangan } \\
(\% 32)\end{array} & \text { Sülfat } \\
\end{array}$ & $\begin{array}{ll}\text { Çinko } & \text { Sülfat } \\
(\% 23) & \end{array}$ & $\begin{array}{ll}\text { Borik } & \text { Asit } \\
(\% 11,3) & \end{array}$ & $\begin{array}{lr}\text { Bakır } & \text { Sülfat } \\
(\% 25) & \end{array}$ & $\begin{array}{l}\text { Potasyum } \\
\text { Klorür }\end{array}$ & $\begin{array}{l}\text { Nitrik Asit } \\
\mathrm{HNO}_{3}\end{array}$ \\
\hline & $\mathrm{MnSO}_{4} \cdot \mathrm{H}_{2} \mathrm{O}$ & $\mathrm{ZnSO}_{4} \cdot 7 \mathrm{H}_{2} \mathrm{O}$ & $\mathrm{H}_{3} \mathrm{BO}_{3}$ & $\mathrm{CuSO}_{4} \cdot 5 \mathrm{H}_{2} \mathrm{O}$ & $\mathrm{KCl}$ & \\
\hline & $0.6 \mathrm{~g}$ & $1.6 \mathrm{~g}$ & $0.4 \mathrm{~g}$ & $0.6 \mathrm{~g}$ & $30 \mathrm{~g}$ & $30 \mathrm{cc}$ \\
\hline
\end{tabular}

Çalışmada, yetiştirme periyodu boyunca plastik sera içi 1şık (lux), sıcaklık $\left({ }^{\circ} \mathrm{C}\right)$ ve oransal nem (\%) değerleri veri kaydedici (KT100, Kimo, Fransa) ile ölçülmüştür. Araştırmada veri kaydedici ile ölçülen 1şık değerlerini PAR (Fotosentetik Aktif Radyasyon)'a dönüştürebilmek için Sunscancanopy analyser (SS1, LI-COR, USA) cihazı kullanılarak günde (sabah; 07.00, öğlen; 12.00 ve akşam; 17.00) üç defa ölçüm yapılmıştır. Ölçümün yapıldığı saatlerde her iki cihazın ölçüm değerleri kıyaslanarak dönüşüm katsayısı $\left(1 \mathrm{PAR}\left(\mathrm{MJ} \mathrm{m} \mathrm{d}^{-2} \mathrm{~d}^{-1}\right)=\right.$ 2400.16 lüx) belirlenmiştir (Kırbay ve Özer, 2015). Çalışmada ışık şiddetinin yoğun olduğu dönemde (Ağustos ayının ortasına kadar), 1şık geçirgenliği \% 50 olan koyu yeşil renkli plastik net ile serada gölgelendirme yapılmıştır. Yetiştiricilik yapılan seranın iklim özellikleri (sıcaklık; ${ }^{\circ} \mathrm{C}$, 1şık; PAR ve oransal nem; $\%)$ değerleri Şekil 1 ve Çizelge 4'de verilmiştir.
Çizelge 4. Sera içi ortalama oransal nem (\%) ve sıcaklık değerleri $\left({ }^{\circ} \mathrm{C}\right)$

\begin{tabular}{lcc}
\hline & $\begin{array}{c}\text { Oransal Nem } \\
(\%)\end{array}$ & $\begin{array}{c}\text { Sicaklık } \\
\left({ }^{\circ} \mathrm{C}\right)\end{array}$ \\
\hline En düşük & 44.6 & 10.4 \\
En yüksek & 88.9 & 26.7 \\
Ortalama & 77.8 & 20.6 \\
\hline
\end{tabular}

Budama, yetiştirme periyodu boyunca sırık domates yetiştiriciliğinde uygulanan yaprak koltuklarından çıkan sürgünler ile sararmış ve hastalıklı yaprakların alınması şeklinde gerçekleştirilmiştir. Özdemir ve Özer (2015)'in Bandita F1 salkım domates çeşidi için belirlemiş oldukları uygulama dikkate alınarak yetiştiricilik periyodu boyunca bitki üzerinde hasat edilen salkımdan sonraki yeşil meyve salkımının altında 2 yaprak 


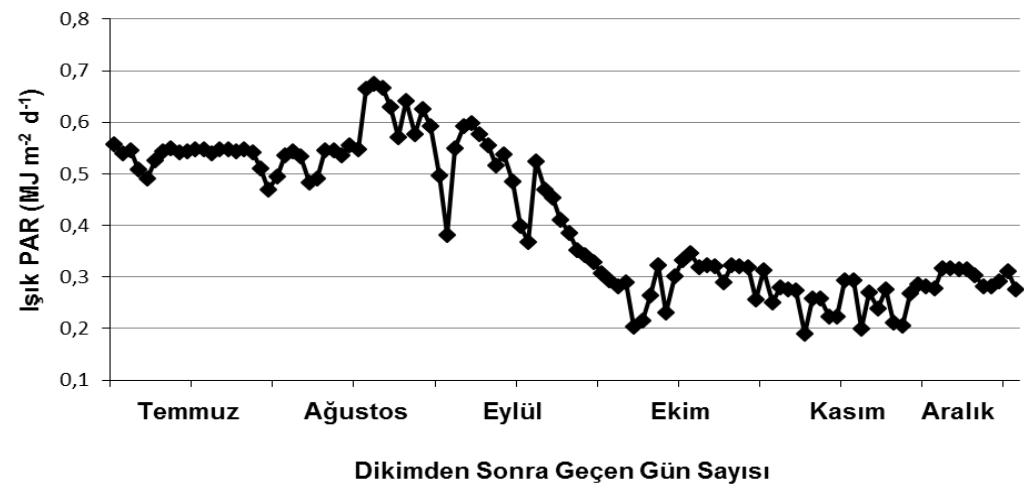

Şekil 1. Çalışmanın yürütüldüğü seranın günlük ortalama ışık değerleri (PAR)

bırakılarak budama uygulaması gerçekleştirilmiştir. Çalışmada, tepe budaması yapılmamıştır.

Meyve kabuk rengi ölçümleri, renk ölçüm aletiyle (Minolta, Tokyo, Japonya) dijital olarak saptanmıştır. Kabuk diş rengi meyvenin tam merkezinden (ekvator bölgesi) 2 yan kısımda okunarak meyve kabuk renk değerleri (L: parlaklık oranı, +a: kırmızı ve $+\mathrm{b}$ : sarı) ölçülmüştür. Elde edilen bu değerlerden kroma ve hue ${ }^{\mathrm{o}}$ (b/a) açısı McGuire (1992)'e göre hesaplanmıştır. Hue ${ }^{\circ}$ açısının değerlendirilmesinde; $0^{\circ}=$ kırmızı-mor, $90^{\circ}=$ sarı, $180^{\circ}=$ mavimsi-yeşil ve $270^{\circ}=$ mavi skalası kullanılmıştır.

Meyve eti sertliği ölçümleri ise hasat edilen domateslerin her iki yüzünde yanak kısmında yaklaşık 1 $\mathrm{cm}$ çapında kabuk keskin bir bıçakla yüzeysel olarak kesilmiş ve ölçümler bu kısımlarda yapılmıştır. Penetrometrenin (4301, Instron, ABD) 5 mm'lik ucunun kabuğu kaldırılan bölgeye yaklaşı $7.4 \mathrm{~mm}$ batırılmasına karşın meyve etinin göstermiş olduğu direnç meyve eti sertliği olarak belirlenmiştir (Kurnaz ve ark., 1992). Suda çözünebilir toplam kuru madde miktarı (SÇKM), ölçüm bitkilerinden alınan olgun meyveden elde edilen meyve suyunda el refraktometresiyle (ATC-I, Atago, Japonya) okunarak yüzde (\%) olarak saptanmıştır.

İlk hasattan son hasat tarihine (15.12.2013) kadar hasat edilen meyvelerin ağırlığı 0.1 g'a duyarlı terazi ile tartılmıştır. Elde edilen meyve ağırlıkların ortalamaları alınarak ortalama meyve ağırlığı $\mathrm{g}$ olarak belirlenmiştir. Hasat edilen meyvelerin ağırlıkları toplanarak bitki başına verim $\mathrm{kg}$ olarak hesaplanmıştır. Meyveler alüminyum folyo tabaklara yerleştirilerek $80^{\circ} \mathrm{C}$ sicaklıktaki etüvde 72 saat süreyle kurutularak kuru ağırlıkları belirlenmiştir. Kuru meyve ağılıkları yaş meyve ağıllıklarına oranlanarak ortalama meyve kuru madde içeriği \% olarak hesaplanmıștır.

Araştırma, 3 tekerrürlü ve her tekerrürde 3 bitki olacak şekilde tesadüf blokları deneme desenine göre kurulmuştur. Çalışma sonucunda elde edilen verilerin değerlendirilmesinde Microsoft Excel 2010 paket programı ve SPSS 17.0 istatistik analiz programı kullanılmıştır. Elde edilen ortalamalar arasındaki farklar Duncan çoklu karşılaştırma testiyle belirlenmiştir.

\section{Bulgular ve Tartışma}

Farklı yetiştirme ortamlarında yetiştirilen domates meyvelerinde $\mathrm{L}$ değerleri bakımından istatistiksel olarak önemli düzeyde fark $(\mathrm{P}<0.05)$ bulunmuştur. Parlaklık, özellikle tüketici tercihleri açısından aranan önemli kalite özelliklerinden birisidir. Toprak ve Gül (2013) domates meyvelerinin $\mathrm{L}$ değerlerinin 46.62 ile 47.44 arasında değiştiğini ve en yüksek parlaklığın Hindistan cevizi lifinden elde edildiğini bildirmişlerdir. Çizelge 5 incelendiğinde, hasat edilen domates meyveleri içerisinde en fazla parlaklık (64.6) kaya yünü ile yetiştiricilik yapılan ortamdan elde edilmiştir. En düşük parlaklık değerinin ise 54.2 ile ortam II uygulamasından elde edildiği belirlenmiştir.

Çizelge 5. Farklı yetiştirme ortamlarının domates meyve rengi (L; Chroma ve $\mathrm{Hue}^{\circ}$ ) değerleri üzerine etkisi

\begin{tabular}{llll}
\hline $\begin{array}{l}\text { Yetiştirme } \\
\text { ortamları }\end{array}$ & $\mathrm{L}$ & Kroma & Hue $^{\mathrm{o}}$ \\
\hline Ortam I & $60.01 \mathrm{~b}$ & $45.05 \mathrm{a}^{*}$ & $0.267 \mathrm{~b}$ \\
Ortam II & $54.24 \mathrm{c}$ & $42.46 \mathrm{~b}$ & $0.220 \mathrm{~b}$ \\
Kaya yünü & $64.63 \mathrm{a}^{*}$ & $46.85 \mathrm{a}$ & $0.455 \mathrm{a}$ \\
Hindistan cevizi lifi & $60.81 \mathrm{~b}$ & $41.63 \mathrm{~b}$ & $0.183 \mathrm{c}^{*}$ \\
\hline$* \mathrm{P}<0.05$ & & &
\end{tabular}

Meyve kabuk renk değerleri $L^{*} a^{*} b^{*}$ olarak ölçülmüştür. $L^{*}$ değeri ölçüm yapılan yüzeyin, 1şığı ne kadar yansıttığını, yani siyahtan beyaza rengin açıklık ve koyuluğunu $(0=$ Beyaz; $100=$ Siyah $)$, $a^{*}$ değeri kırmızıdan (pozitif) yeşile (negatif); $b^{*}$ değeri ise sarıdan (pozitif) maviye (negatif) renk değişimlerini belirtmektedir. $\mathrm{Hue}^{\circ}$ açısı, meyve renginin niteliğini belirtir $\left(0^{\circ}=\right.$ kırmızı-pembe, $90^{\circ}=$ sarı, $180^{\circ}=$ yeşil, $270^{\circ}=$ mavi). Kroma değeri ise, rengin canlılığını/doygunluğunu belirtmekte olup; 0 değeri griakromatik (renksiz) bir rengi ifade ederken, değerin artmasıyla rengin canlılı̆g artmaktadır (McGuire, 1992). Domates insan beslenmesi açısından önemli likopen, fenolik bileşikler ve $\mathrm{C}$ vitamini gibi antioksidan maddeler içermektedir (Abushita ve ark., 1997; Clinton, 
1998; Kaur ve ark., 2002; Toor ve ark., 2006). Domatese kırmızı rengi veren likopen, domatesin karotenoit içeriğinin \%90'ını oluşturmaktadır. Rengin kırmızılığ1 ve doygunluğu likopen içeriğinin yüksek olmasının göstergesidir (Shi ve LeMaguer, 2000; Toor ve ark., 2006). Çalışmada elde edilen sonuçlara göre en yüksek kroma 46.8 ile kaya yünü, en düşük kroma değeri ise 41.6 ile Hindistan cevizi lifi yetiştirme ortamındaki bitkilerin meyvelerinden tespit edilmiştir. En düşük hue ${ }^{0}$ açısı değerinin (0.18) Hindistan cevizi lifi, en yüksek hue ${ }^{\circ}$ açısı (0.45) ile kaya yünü yetiştirme ortamından elde edildiği belirlenmiştir (Çizelge 5). Önceki çalışmalarda kroma değerinin 30.98 ile 39.34 ve hue $^{\mathrm{o}}$ açısının ise 60.48 ile 64.49 değerleri arasında değiş̧tiği, en yüksek değerin ise perlit kullanılan uygulamalardan elde edildiği aktarılmıştır (Toprak ve Gül, 2013). Bizim çalışmamızda ise en yüksek parlaklık (64.63) ve kroma (46.85) değerleri kaya yünü uygulamasından elde edilirken en iyi kırmızı rengin (0.18) Hindistan cevizi uygulamasından elde edildiği tespit edilmiştir.

Bulgularımızı incelediğimizde en yüksek meyve eti sertliğinin $(44.96 \mathrm{~N})$ organik madde miktarı en düşük (\%0) olan kaya yünü uygulamasındaki bitkilerden elde edilen meyvelerden belirlenmiştir.

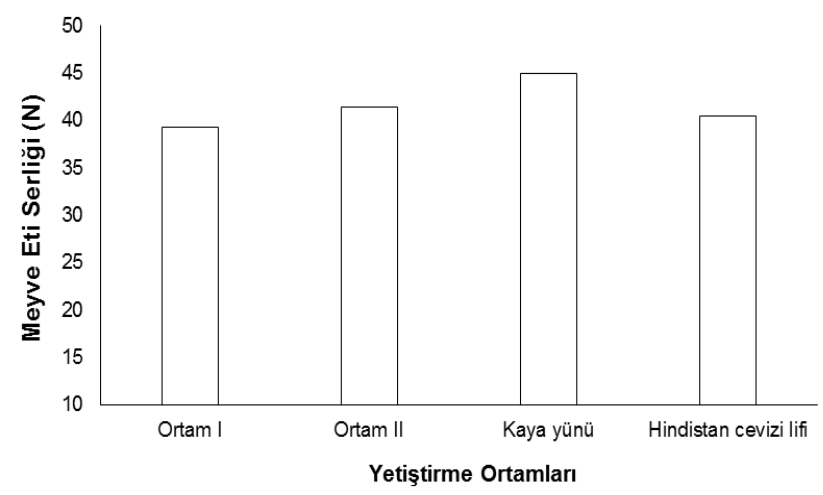

Şekil 2. Farklı yetiştirme ortamlarının meyve eti sertliği (N) üzerine etkisi

Toprak ve Gül (2013), yaptıkları çalışmada domateste en yüksek meyve eti sertliğinin $(59.39 \mathrm{~N})$ organik madde miktarı düşük olan perlit ortamından, en düşük değerin ise $50.18 \mathrm{~N}$ ile Hindistan cevizi lifi ortamından elde edildiğini belirtmişlerdir. Çalışmamızda da meyve eti sertliğinin organik madde miktarı yüksek olan ortam I ve Hindistan cevizi lifi ortamı kullanıldığında azaldığı $(39.24$ ve $40.47 \mathrm{~N})$ belirlenmiştir (Çizelge 2 ve Şekil 2). Çalışmamızda, farklı yetiştirme ortamlarıyla yetiştiricilik yapılmasının meyve eti sertliğini $(\mathrm{N})$ önemli düzeyde etkilenmediği tespit edilmiştir.

Meyve kuru madde içeriği \%6.38 ile 6.83 arasında değişim göstermiştir (Şekil 3). En yüksek değerin $\% 6.83$ ile kaya yünü ortamı kullanılan uygulamadan elde edilmesine rağmen, farklı yetiştirme ortamlarının meyve kuru madde içeriği (\%) üzerine etkisi istatistiksel olarak önemsiz bulunmuştur. Toprak ve Gül, (2013) topraksız domates yetiştiriciliğinde meyve kuru madde içeriğinin \%5.16 ile 6.3 değerleri arasında değiştiği ve en yüksek meyve kuru madde miktarının \%6.3 ile Hindistan cevizi lifi kullanılan ortamdaki bitkilerin meyvelerinden tespit edildiğini aktarmışlardır. Danneh ve ark. (2015) ise en yüksek meyve kuru ağırlığının $\% 6.3$ ile koyun yünü ortamından elde edildiğini bildirmişlerdir. $\mathrm{Bu}$ yönüyle elde ettiğimiz bulgular yapılan çalışmalarla benzerlik göstermiştir.

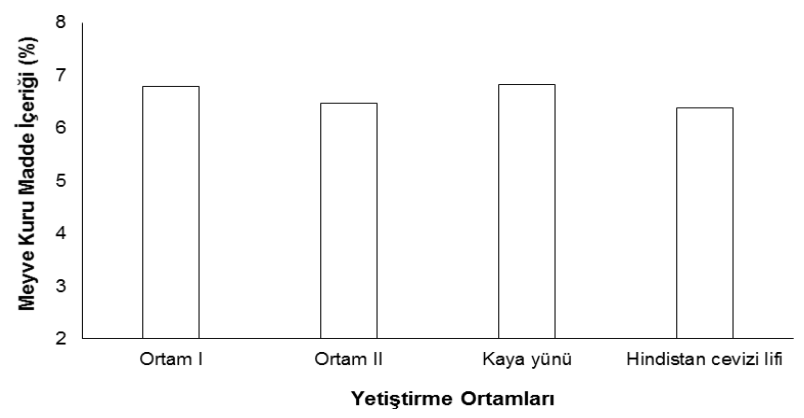

Şekil 3. Farklı yetiştirme ortamlarının meyve kuru madde içeriği (\%) üzerine etkisi

Sonuçlara göre domates meyvelerinde SÇKM \%6.03 ile \%6.73 arasında değişim göstermiştir. Yetiştirme ortamlarının SÇKM üzerine etkisi istatistiki olarak önemli bulunmuştur $(\mathrm{P}<0.05)$. En yüksek $\mathrm{SCCKM}$ değeri 6.73 ile ortam I, en düşük SÇKM değeri ise 6.03 ile yetiştirme ortamı olarak kaya yününün kullanıldığı uygulamadaki bitkilerin meyvelerinden elde edilmiştir (Şekil 4). Domateste suda çözünebilen kuru madde içeriğinin \%2.9 ile 7 arasında değiştiği bildirilmektedir (Bargefurd ve Harker, 1998; Şalk ve ark., 2008; Ünlü ve Padem, 2009; Danneh ve ark., 2015). Farklı bir çalışmada domates meyvelerinin SÇKM değerlerinin \%5.10 ile 5.56 arasında değiştiği ve en yüksek değerin ise Hindistan cevizi lifi ortamındaki meyvelerden elde edildiği bildirilmiştir (Toprak ve Gül, 2013). Benzer sonuçlar bizim çalışmamızda da elde edilirken, Hindistan cevizi lifinde SÇKM değerinin \%6.6 olduğu tespit edilmiştir (Şekil 4).

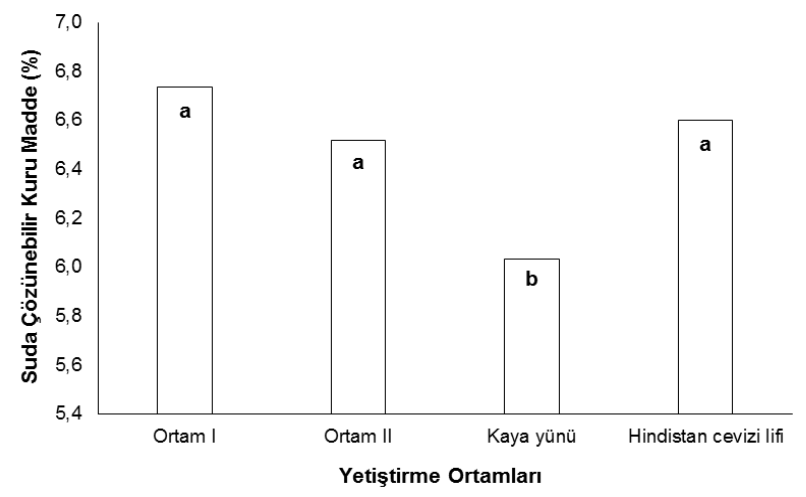

Şekil 4. Farklı yetiştirme ortamlarının suda çözünebilir kuru madde $(\%)$ üzerine etkisi $(\mathrm{P}<0.05)$

Hasat edilecek kısımlarda daha fazla kuru madde birikimi iyi bir bitki besleme ile arttırlabilmektedir 
(Charles ve ark., 1986). Çiftlik gübresi uygulamalarında çiftlik gübresi dozunun artı̧ına paralel olarak suda çözünebilir kuru madde değerlerinin azaldığ belirtilmiştir (Ünlü ve Padem, 2009). Ancak, bizim çalışmamızda ortamlardaki organik madde miktarı artışı ile suda çözünebilir kuru maddenin azalmadığı tespit edilmiştir.

Çalışmada, farklı yetiştirme ortamlarının bitki başına verim $(\mathrm{kg})$ ve ortalama meyve ağırlı̆̆ $1(\mathrm{~g})$ değerleri üzerine etkisi istatistiksel olarak önemsiz bulunmuştur. Elde edilen sonuçlar doğrultusunda bitki başına verim $2.43 \mathrm{~kg}$ (ortam I ve kaya yünü) ile $3.07 \mathrm{~kg}$ (Hindistan cevizi lifi) değerleri arasında değişim göstermiştir (Şekil $5)$.

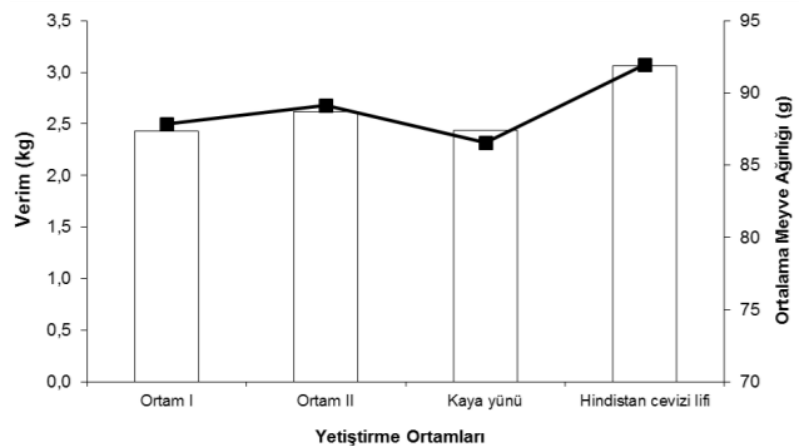

Şekil 5. Farklı yetiştirme ortamlarının verim $(\mathrm{kg})$ ve ortalama meyve ağırlığı $(\mathrm{g})$ üzerine etkisi

Benzer sonuçlar Toprak ve Gül (2013) tarafından aktarılmış, çalışmalarında bitki başına verimin 2.83 ile $2.9 \mathrm{~kg}$ arasında değiştiği ve en yüksek verimin Hindistan cevizi lifi uygulamasından elde edildiğini belirlemişlerdir. Bozköylü (2008) ise topraksız domates yetiştiriciliğinde $10.650 \mathrm{~kg} \mathrm{da}^{-1}$ verim elde etmiştir. Bizim çalışmamızda, elde edilen dekara verim ise $11.790 \mathrm{~kg} \mathrm{da}^{-1}$ olarak belirlenmiştir. Ayrıca farklı çalışmalarda verim yönünden benzer sonuçlar elde edilmesine rağmen kullanılan yetiştirme ortamları arasında istatistiki fark tespit edilmemiştir (Reis ve ark., 2001; Scettrini ve Jelmini, 2004; Varış ve ark., 2004; Allaire ve ark., 2005). Danneh ve ark. (2015) ise topraksız olarak yetiştirilen domateslerde verimin 10.4 ile $13.8 \mathrm{~kg} \mathrm{bitki}^{-1}$ değerleri arasında değiştiğini ve en yüksek verimin ise kaya yünü ortamındaki bitkilerden elde edildiğini aktarmışlardır. Bu çalışmanın verim değerlerinin bizim bulgularımızdan yüksek olmasının nedeni kontrollü atmosferli bir serada uzun bir yetiştirme periyodu boyunca gerçekleşmiş olmasıdır. Araştırmada, ortalama meyve ağırlığı değerleri ise 86.5 g (kaya yünü) ile $91.9 \mathrm{~g}$ (Hindistan cevizi lifi) arasında değişim göstermiştir (Şekil 5). Benzer sonuçların elde edildiği bir çalışmada domateste ortalama meyve ağırlığının 87.5 ile $92.5 \mathrm{~g}$ arasında değiştiği ve en yüksek ortalama meyve ağırlığının kaya yünü ortamından elde edildiği bildirilmiştir (Danneh ve ark., 2015).

Sebze yetiştiriciliğinde başarının en önemli göstergesi verimliliktir. Bitkilerde, verimlilik üzerine 1şık şiddeti, sıcaklık, sulama, gübreleme ve budama gibi faktörlerin etkilerinin önemi büyüktür (Uzun, 2000; Özdemir ve Özer, 2015). Bu faktörlerden organik maddenin gübreleme ile arttırılması domates yetiştiriciliğinde verimin önemli düzeyde arttırmaktadır (Stephens ve ark., 1989; Kozak, 1996; Ceylan ve ark., 2000; Beşirli ve ark., 2001; Uysal, 2005). Topraksız yetiştiricilikte ise, yetiştirme ortamının organik madde içeriğinin verim yönünden önemli bir avantaj sağladığı bildirilmiştir (Abak ve ark., 1992; Abak ve Çelikel, 1994). Çalışmada Hindistan cevizi lifi yetiştirme ortamında verim değerlerinin yüksek çıkması (Şekil 5) Hindistan cevizi lifinin organik madde içeriğinin en yüksek olması (Çizelge 2) ile açıklanabilir. Bu durumu önceki çalışma sonuçları desteklemektedir.

\section{Sonuç}

Ülkemizde topraksız tarımda yaygın olarak kullanılan ortamlardan kaya yünü ve Hindistan cevizi lifi temini tamamen dişa bağımlı olarak gerçekleşmektedir. $\mathrm{Bu}$ durum girdi masraflarını arttırarak, karlılığı önemli derecede etkilemektedir. Topraksız tarımda kullanılan yetiştirme ortamlarının bölgesel organik atıklardan elde edilmesi üretim maliyetlerini düşürebilecektir. Ayrıca, alternatif yetiştirme ortamları kaya yünü ve Hindistan cevizi lifi gibi ithal edilen ortamlara talebi azaltarak ülke ekonomisine katk1 sağlayacaktır.

Yapmış olduğumuz çalışmada en yüksek verim dekara 11.8 ton olarak Hindistan cevizi lifinden elde edilmiştir. Bölgesel organik atıklardan oluşturulan, II. ortam ile dekara 10.5 ton elde edilirken I. ortamda dekara 9.9 ton ürün elde edilmiştir. Toplam verim bölgesel atıklardan oluşturulan ortamlarda, Hindistan cevizi lifine göre az olsa da bu durumun yetiştirme ortamlarının geliștirilmesi ile değiştirilebileceği düşünülmektedir. Çünkü hazırladığımız iki ortamda (I. ve II.) aynı materyaller kullanılmasına rağmen oranlarındaki değişiklik verimi önemli derecede etkilemiştir. Sonuç olarak, bölgesel organik atıklardan elde edilen ortamlarda aynı materyaller kullanılmasina rağmen oranlarındaki değişimler verimliliği önemli düzeyde etkilemiştir. Elde edilen veriler 1şı̆̆ında bölgesel organik atıklardan oluşturulan yetiştirme ortamlarının topraksız tarımda yaygın olarak kullanılan ve ticari olarak yurt dışından ithal edilen yetiştirme ortamlarına alternatif olabilme potansiyelinin yüksek olabileceği düşünülmektedir. Ülkemizin değişik bölgelerinde bulunan tarımsal atıkların kompostlandıktan sonra farklı karışımlarının alternatif yetiştirme ortamı olarak kullanılması tarımsal sürdürebilirlik ve verimliliğe katkı sunacaktır.

\section{Teşekkür}

Yazarlar olarak, bu çalışmanın PYO. ZRT.1904.3.023 numaralı proje ile desteklenmesinden dolay1, Ondokuz Mayıs Üniversitesi Proje Yönetim Ofisine teşekkür ederiz. Ayrıca, çalışmanın konusunun 
belirlenmesi ve yürütülmesi aşamasında katkılarından dolayı Prof. Dr. Sezgin Uzun'a teşekkür ederiz.

\section{Kaynaklar}

Abak, K., Çelikel, G., 1994. Comparison of some Turkish originated organic and inorganic substrates for tomato soilless culture. Acta Hortic., 366: 423-427.

Abak, K., Yanmaz, R., İlbay, M.E., 1992. Kullanılmış mantar kompostunun sera biber yetiştiriciliğinde kullanılması. Türkiye I Ulusal Bahçe Bitkileri Kongresi, Cilt II, 367370, 13-16 Ekim, Bornova, İzmir.

Abushita, A.A., Hebshi, E.A., Daood, H.G., Biacs, P.A., 1997. Determination of antioxidant vitamins in tomatoes. Food Chem., 60: 207-212.

Allaire, S.E., Caron, J., Menard, C., Dorais, M., 2005. Potential replacements for rockwool as growing substrate for greenhouse tomato. Can. J. Soil Sci., 85(1): 67-74.

Aydoğan, N.G., Gül, A., 1999. Topraksız kavun yetiştiriciliğinde torba özelliklerinin bitki gelişimi ve verime etkileri. Türkiye 3. Ulusal Bahçe Bitkileri Kongresi, 343-347.

Bargefurd, B.R., Harker, T.C., 1998. Fresh market tomato cultivar evaluation. Centers at Piketon, exploring economic opportunities. Ohio State University Extension Enterprise Center 1864 Shyville Road. Piketon, Ohio.

Başar, H., 1995. Seralarda damla gübreleme. Hasad, 123: 2024.

Beşirli, G., Sürmeli, N., Sönmez, İ., Kasım, M. U., Başay, S., Karı, Ü., Şarlar, G., Çetin, K., Erdoğan, S., Çelikel F.G., Pezikoğlu, F., Efe, E., Hantaş, C., Uzunoğulları, N., Cebel, N., Güçdemir, İ.H., Keçeci, M., Güçlü, D., Tuncer. A.N., 2001. Domatesin organik tarım koşullarında yetiştirilebilirliğinin araştırılması, Türkiye II. Ekolojik Tarım Sempozyumu, 256-265, 14-16 Kasım, Antalya.

Bozköylü, A., 2008. Sera topraksız domates yetiştiriciliğinde kimyasal ve organik gübrelemenin karşılaştırılması. Yüksek Lisans Tezi, Çukurova Üniversitesi Fen Bilimleri Enstitüsü, Adana.

Ceylan, Ş., Yoldaş, F., Mordoğan, N., Çakıcı, H., 2000. Domates yetiştiriciliğinde farklı hayvansal gübrelerin verim ve kaliteye etkisi. 3. Sebze Tarımı Sempozyumu, 51-55, 11-13 Eylül, Isparta.

Charles-Edwarrds, A.D., Doley, D., Rimmington, G.M., 1986. Modelling plant growth and development. Academic Press, 235, Sydney.

Clinton, S.K., 1998. Lycopene: chemistry, biology and implications for human health and disease. Nut. Rev., 56: 35-51.

Çıtak, S., Sönmez, S., Öktüren, F., 2007 Bitkisel kökenli atıkların tarımda kullanılabilme olanakları. http://batem.gov.tr/yayinlar/derim/2006/41-53.pdf. (Ulaşım: 16 Eylül 2015)

Danneh, D., Suhl, J., Ulrichs, C., Schmidt, U. 2015. Evaluation of substitutes for rock wool as growing substrate for hydroponic tomato production. J. Appl. Bot. Food Qual., 88: 68-77.

FAO, 2015. Bitkisel Üretim istatistikleri. http://faostat3.fao.org/home/E (Ulaşım: 10 Eylül 2015)

Frolking, S, Roulet, N.T, Moore, T.R, Richard, P.J.H., Lavoie, M., Muller, S.D., 2001. Modeling northern peatland decomposition and peat accumulation. Ecosystems, 4: 479-498.

Gül, A., 2008. Topraksız Tarım, Hasad Yayıncılık, 144s.
Jackson, M.L. 1967. Soil chemical analysis. Prentice-Hall of India Private Limt. New Delhi. 907 s.

Kacar, B., 1994. Bitki ve Toprağın Kimyasal Analizleri III, Ankara Üniversitesi Ziraat Fakültesi Yayınları, Ankara.

Kaur, R., Savage, G.P., Dutta, P.C., 2002. Antioxidant vitamins in four commercially grown tomato cultivars. P. Nutrit. Soc. New Zealand, 27: 69-74.

Kırbay, E., Özer, H., 2015. Farklı gölgeleme uygulamalarının örtüaltında organik olarak yetiştirilen hıyarın (Cucumis sativus L.) verim ve kalite üzerine etkisi. Uluslararas1 Tarım ve Yaban Hayatı Bilimleri Dergisi, 1(1): 7-14.

Kozak, B., 1996. Örtü altı domates yetiștiriciliğinde organik gübreleme ve mineral gübrelemenin ürün kalitesi ile bazı hastalıklara etkisi. Yüksek Lisans Tezi, Çukurova Üniversitesi Fen Bilimleri Enstitüsü, Adana, 58127.

Kurnaz, Ş., Özcan, M., Kopuzoğlu, N., Demirsoy, H., 1992. Samsun'da yetiştirilen deveci Armutları üzerine NAA, NAD, Carbaryl ve elle seyreltme uygulamalarının etkileri. Bahçe, 21(1-2): 3-8.

Leonardi, C. 2004. Growing media. Regional Training Workshop on Soilless Culture Technologies. 83-92, 3-5 March, İzmir-Turkey,

McGuire, R.G., 1992. Reporting of objective color measurements. HortScience, 27: 1254-1255.

Özdemir, A., Özer, H., 2015. Effect of leaf pruning on yield and quality of organically grown grape tomato (Solanum lycopersicum L.). Anadolu J. Agric.Sci., 30(1): 1-6.

Özer, H., Uzun, S., 2013. Açıkta organik domates (Solanum lycopersicum L.) yetiştiriciliğinde farklı organik gübrelerin bazı verim ve kalite parametrelerine etkisi, Türkiye V. Organik Tarım Sempozyumu, Bildiri Kitabı-1, 1-8, 25-27 Eylül, Samsun

Özgümüş, A., Kaplan, M., 1992. Bitki yetiştirme ortamı olarak perlitin önemi ve topraksız kültürde perlitten yararlanma olanakları. Türkiye I. Tarımda Perlit Sempozyumu, 49-57, 29-30 Haziran, İzmir.

Reis, M., Inácio, H., Rosa, A., Caccedil, J., Monteiro, A., 2001. Grape Marc compost as an alternative growing media for greenhouse tomato. Acta Hortic., 554: 75-82.

Scettrini, S., Jelmini, G., 2004. Test of different substrates for soilless cultivation of tomato. Revue Suisse de Viticulture. Arboriculture et Horticulture, 36 (5): 289-294.

Sevgican, A., 1989. Örtüaltı Sebzeciliği. TAV Yayınları, Yayın No: 19. Yalova

Sevgican, A., 2003. Örtüaltı Sebzeciliği (Topraksız Tarım) Genişletilmiş 2. basım Cilt II, Ege Üniversitesi Ziraat Fakültesi Yayınları No: 526, Ege Üniversitesi. Basımevi, Bornova-İzmir.

Shi, J., LeMaguer, M., 2000. Lycopene in tomatoes; chemical and physical properties affected by food processing. Crit. Rev. Biotech., 20: 293-334.

Stephens, J.M., Henry, G.C., Castro, B.F., Bennett, D.L., 1989. Mushroom compost as a soil amendment for vegetable gardens. P. Florida State Hortic. Soci., 102: 108111.

Şalk, A., Arın L., Deveci, M., Polat, S., 2008. Özel Sebzecilik. Onur Grafik Matbaa ve Reklam Hizmetleri, 428s, Tekirdağ.

Şentürk, T., 2012. Gıda Tarım ve Hayvancılık Bakanlığı Bitkisel Üretim Genel Müdür Yardımcısı TSE Standart Ekonomik ve Teknik Dergisi Nisan, 599: 8-16.

Toor, R.K., Savage, G.P., Heeb, A., 2006. Influence of different types of fertilisers on the major antioxidant components of tomatoes. J. Food Compos. Analy., 19: 2027.

Toprak, E., Gül, A., 2013.Topraksız tarımda kullanılan ortam 
domates verimi ve kalitesini etkiliyor mu? Tarım Bilimleri Araştırma Dergisi, 6 (2): 41-47.

Tüzel, Y., Gül, A., 2008. Seracılıkta Yeni Gelişmeler. Ege Tarımsal Araş. Ens. Yayın No. 133, 145-160.

Tüzel, Y., Gül, A., Daşgan, H.Y., Öztekin, G.B., Engindemiz S., Boyac1, H.F., 2015. Örtüaltı yetiştiriciliğinde değişimler ve yeni arayışlar. Türkiye Ziraat Mühendisliği VIII. Teknik kongresi, Bildiriler Kitab1-I, 685-709, 12-16 Ocak, Ankara.

Uysal, F., 2005. Farklı organik materyallerin organik domates yetiştiriciliğinde kullanılabilirliği, Yüksek Lisans Tezi, Gaziosmanpaşa Üniversitesi Fen Bilimleri Enstitüsü, Tokat.
Uzun, S., 2000. Sıcaklık ve 1şığın bitki büyüme, gelişme ve verimine etkisi (III. Verim). OMÜ Zir. Fak. Derg., 15(1): 105-108.

Ünlü, H., Padem, H., 2009. Organik domates yetiştiriciliğinde çiftlik gübresi, mikrobiyal gübre ve bitki aktivatörü kullanımının verim ve kalite özellikleri üzerine etkileri. Ekoloji, 19(73): 1-9.

Varış, S., Çinkılıç, H., Koral, S.P., Butt, J.S., Çinkılıç, L., 2004. Öğütülmüş cibre-cüruf (ÖCC) harc1. Hasad Dergisi, 243: 26-34.

Varış, S., Eminoğlu, F.S., 2003. Örtüaltı tarımında kullanılan ve kullanılabilinecek olan ortamların fiziksel ve kimyasal özellikleri. Hasad, Eylül, 220: 46-57. 